Review Article

\title{
High-Temperature Properties of a Long-Span Double-Deck Suspension Bridge under a Tanker Fire
}

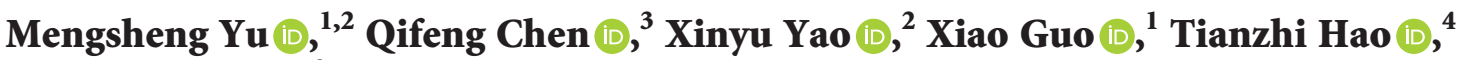 \\ and Hua Wang $\mathbb{B D}^{2}$
}

${ }^{1}$ College of Civil Engineering and Architecture, Guangxi University, Nanning 530007, China

${ }^{2}$ Guangxi Transportation Science and Technology Group Co., Ltd., Nanning 530007, China

${ }^{3}$ Guangxi University of Science and Technology, Liuzhou 545006, China

${ }^{4}$ Guangxi Beitou Traffic Maintenance Technology Group Co., Ltd., Nanning 530029, China

Correspondence should be addressed to Qifeng Chen; chenqifeng3333@163.com

Received 22 April 2021; Revised 20 August 2021; Accepted 7 September 2021; Published 30 September 2021

Academic Editor: Vasant Matsagar

Copyright (c) 2021 Mengsheng Yu et al. This is an open access article distributed under the Creative Commons Attribution License, which permits unrestricted use, distribution, and reproduction in any medium, provided the original work is properly cited.

This paper presents a numerical study on the high-temperature mechanical properties of a long-span double-deck suspension bridge. The main focus of this paper is the behavior analysis of Wuhan Yangtze River Bridge. A three-dimensional thermal model of the bridge was established by the Fire Dynamics software (FDS) to obtain the 3D temperature field distribution, and the thermal analysis result was then applied to the three-dimensional finite element model of the suspension bridge. The shortest failure time of the main cable and sling was determined to obtain the rescue time of a bridge fire. According to the calculation results of the suspension bridge under a tanker fire initiated at the upper deck of the bridge, the middle lane in the upper deck of the suspension bridge was determined to be a safe lane. Thus, the tanker should be guided to go in this lane of the bridge. The numerical analysis of the experimental results shows that when the fuel tanker is located on the upper and lower floors of the bridge, the bridge structure is affected by the fire. When the oil tanker burns in the outermost lane of the upper bridge, it will have a great impact on the main cables and slings of the bridge. When the fuel tanker burns in the lower nonmotorized lane of the bridge, it will have a great impact on the upper stiffening beam steel plates and truss rods.

\section{Introduction}

When the suspension bridge structure is damaged during a tanker fire, it could result in a considerable loss of human life and economic properties. Meanwhile, a damaged suspension bridge might paralyze a city's traffic and cause immeasurable loss of economic profits. With the increasing number of bridge structures, the probability and number of tanker fires have also shown an upward trend [1-3]. Due to many excellent properties, such as light weight, high strength, and ductility, steel has become the most common material for suspension bridges. However, the fire resistance of steel is poor. The elastic modulus and strength of steel are significantly reduced as the temperature increases. Once a tanker fire happens on a bridge, a high-temperature field will occur and the temperature of the main cable, suspender cable, deck pavement, and stiffening beam of the suspension bridge will increase rapidly. Due to the process of thermal convection and radiation, the corresponding elastic modulus and strengths will significantly decrease. At the same time, the stress will be redistributed under the high temperature, resulting in a large deflection of the bridge. Without timely rescue measures, the bridge structure will be partially or completely damaged as the temperature rises.

In recent years, researchers have carried out a large number of structural fire studies. In 2013, ANSYS was used to study the temperature rise curve of the key parts of the steel girder bridge during a fire, as well as the maximum temperature. According to the principle of thermal-structure coupling, the relationship between the strength of the steel structure and time was calculated and the timestructure displacement curve was obtained. In 2013, 
Venkatesh et al. [4] used ANSYS to analyze the mechanical properties of a simply supported girder bridge under fire from two different temperature profiles. Venkatesh pointed out that the fire resistance of the composite bridges was better than that of steel bridges and concrete bridges. In 2014, Alos-Moya [5] studied the change in the high-temperature field of the steel bridge with time when the tanktruck fire was located under the viaduct with CFD software and analyzed the stress and deflection of the steel bridge at high temperature with another type of software; finally, the damage time of the bridge was obtained. The results of the study are very close to the destruction time and form of an actual bridge. In 2015, Peris-Sayol [6] used Fire Dynamics software (FDS) to study the mechanical effects of the steel bridge under fire from the geometric parameters of the bridge, the modeling method, the location of the fire, and the surrounding environment; then, the most dangerous fire scenario of the bridge was obtained. He also pointed out that the finite element software can calculate and predict the destruction time of a bridge. In 2015, the study in [7] compared experimental and finite element results to systematically analyze the mechanical behavior of a steelconcrete composite girder under fire. The effects of different dead-load and live-load levels, different girder webs, and stiffener sizes on the failure mode of the bridge were studied. The failure time of the steel-concrete composite beam bridge under different fire conditions was obtained.

The research of bridge fires is still in its infancy, as fire experiments are expensive, and experimental results are influenced by various factors, resulting in large randomicity. Moreover, the structure in numerical simulation is divided into line units that are mainly based on one-dimensional or two-dimensional simplified methods $[8,9]$. Recently, the problems in the existing literature [10-17] in the study of bridge fire resistance are categorized into the following groups: (1) Thermal engineering parameters and mechanical parameters of the research results are discrete. The use of single thermal parameter can lead to calculation error of the temperature field of the bridge structure, which will affect the mechanical properties of the bridge structure at high temperatures. (2) When Fire Dynamics software is used to simulate the temperature field, the simplified method is usually adopted. The surface of the bridge near the fire is defined as a heating surface that remains unchanged; however, convection and radiation are the main means of heat transfer in a fire, and the convective and radiative surface of the bridge in the fire will change as the fire progresses; thus, this simulation method cannot accurately simulate the radiation and convection processes of the fire source dynamically. (3) It is fairly complicated to analyse mechanical behavior of double steel truss girder suspension bridges during a fire. As the components in the global structure are constrained by the adjacent ones, some scholars hold the view that the global failure criteria of the traditional steel structure have limitations, which does not match the actual situation, and some parts of the bridge are likely to have other forms of local damage before the bridge is destroyed as a whole. (4) Due to the influence of fire location, the fire resistance calculation of the double-deck bridge is obviously different from that of the existing singledeck bridge. The dangerous fire situation and the key parts of the failure time differ considerably from those of a singledeck bridge. The existing research studies mainly focus on the reinforcement of the bridge structure after the fire, but the quantitative failure time and the corresponding fire rescue time of a large-span bridge are not provided.

In this paper, we take the Yangtze River Bridge in Wuhan as a presentative example, and the fire-resistance performance of the large-span double-deck highway suspension bridge, which is an important urban passage with heavy traffic and high fire risk, is studied. A thermal analysis model and a mechanical analysis model of a suspension bridge were established by using FDS and the finite element software ANSYS, respectively. Besides, solid elements were used in key parts of the model, and truss units were used in other parts. This simulation method can accurately calculate the temperature field distribution of the key parts of the suspension bridge according to the number of model units and connect the main components to the whole bridge. In the finite element model of mechanics, the elastic modulus and strength of the changed steel can be defined by the temperature load, and the temperature in the tank-truck fire is a function of time, so the finite element model of the mechanics can be calculated by the indirect coupling method to obtain the change with time. The elastic modulus and strength of the steel, finally, combined with the dead load and live load of the bridge, and the high-temperature mechanical properties of the suspension bridge over time can be analyzed. The mechanical properties of the bridge under high temperature are calculated according to the above calculation principle, and the damage time and best rescue time of the bridge fire are obtained, which provides the technical basis for fire-resistance design of the bridge.

\section{Engineering Situation}

Wuhan Yangtze River Bridge is a double-deck steel truss bridge with a total length of $4.3 \mathrm{~km}$. It is located $3.2 \mathrm{~km}$ from the Parrot Island Yangtze River and $2.8 \mathrm{~km}$ from the Baishazhou Bridge. The route starts from the Hanyang Guobo overpass, going through Parrot Avenue and Riverside Avenue, crossing over the Yangtze River, and finally ending at the Wuchang Batan overpass. The main bridge is a single-span double-deck steel truss girder bridge with a main span, and the steel truss is a Warren truss. The main span is 1700 meters, the side span is 465 meters, the main side span is 0.274 meters, and the rise-span ratio of the main span is $1 /$ 9. The general layout of main bridge is shown in Figure 1.

The standard tensile strength of the main cable is $1960 \mathrm{MPa}$. The whole bridge is arranged in parallel with two main cables, and the distance between the cables is $28 \mathrm{~m}$. Each cable contains 271 strands, and each cable consists of 91 galvanized aluminum alloy-coated high-strength steel wires with a diameter of $6.2 \mathrm{~mm}$. When the main cable is molded, there is $18 \%$ porosity in the cable clamp and the diameter is $1075 \mathrm{~mm}$. After it is pressed into a circle, the porosity of the outside cable clamp is $20 \%$ and the diameter is $1088 \mathrm{~mm}$. The main cable cross section is shown in Figure 2. 


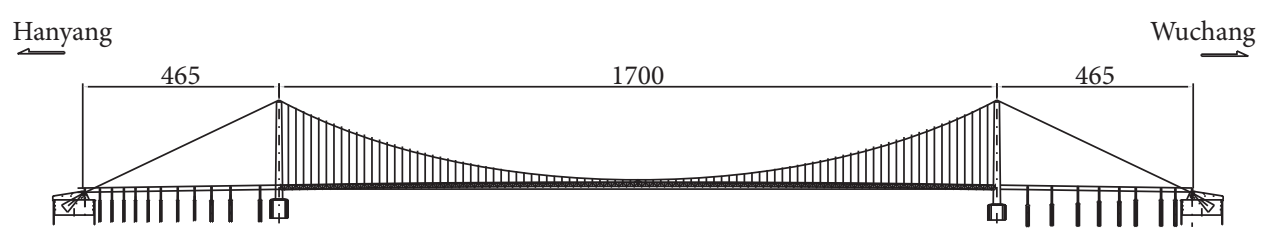

FIGURE 1: General arrangement of the main bridge (unit: $\mathrm{m}$ ).

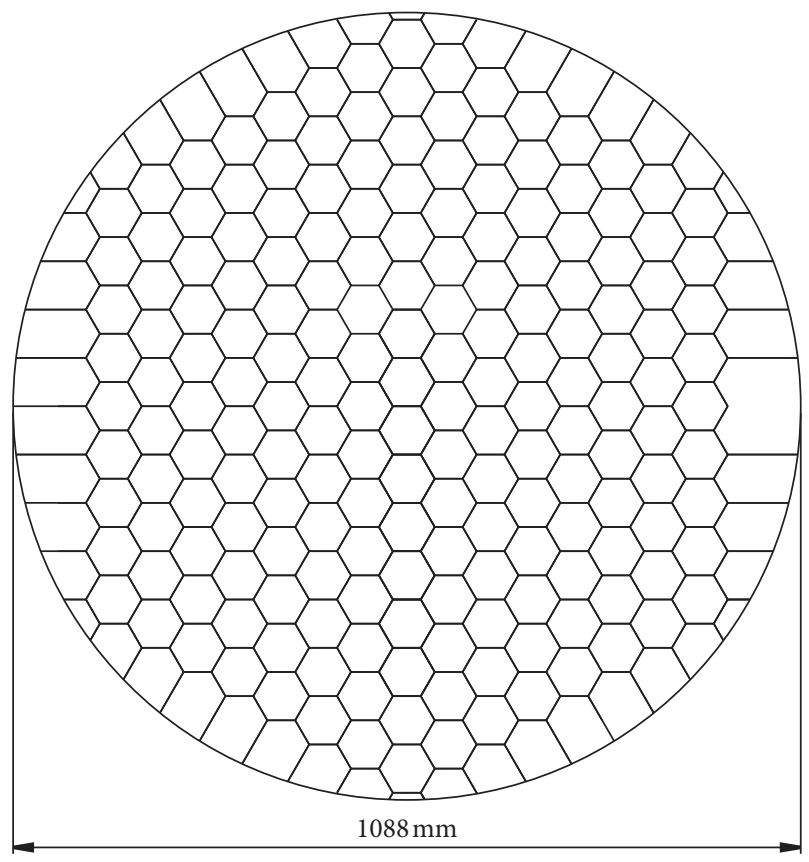

Figure 2: Cross-section arrangement diagram of the main cable.

The nominal diameter of the suspender cable is $70 \mathrm{~mm}$, and the standard tensile strength is $1870 \mathrm{MPa}$. Each lifting point is set with six suspender cables.

The vertical distance of the suspender cable is 18 meters. The structure form is $8 \times 41 \mathrm{WS}+\mathrm{IWR}$, and the design safety factor is $K \geq 4.0$. The cross section of the suspender cable is shown in Figure 3.

The stiffened beam material is $\mathrm{q} 345 \mathrm{qD}$, and the height of the truss is $10 \mathrm{~m}$. The height of the segment is $9 \mathrm{~m}$, while the center distance of the main trusses on both sides of the main beam is $28 \mathrm{~m}$. The main truss is a Warren truss, and the upper chord, lower chord, and oblique web are boxshaped.

The vertical bar is an I-shaped cross section. The upper and lower chords of the main truss have integral gussets and are welded to the oblique webs through the gussets.

\section{Establishment of the Thermal Analysis Model of Yangtze River Bridge}

3.1. Thermal Analysis Model of the Temperature Field of the Tanker. FDS is used to establish the thermal analysis model of the mid-span of Yangtze River Bridge. FDS is based on fluid dynamics equations to perform fluid simulation calculations. To use this equation, the calculation space must

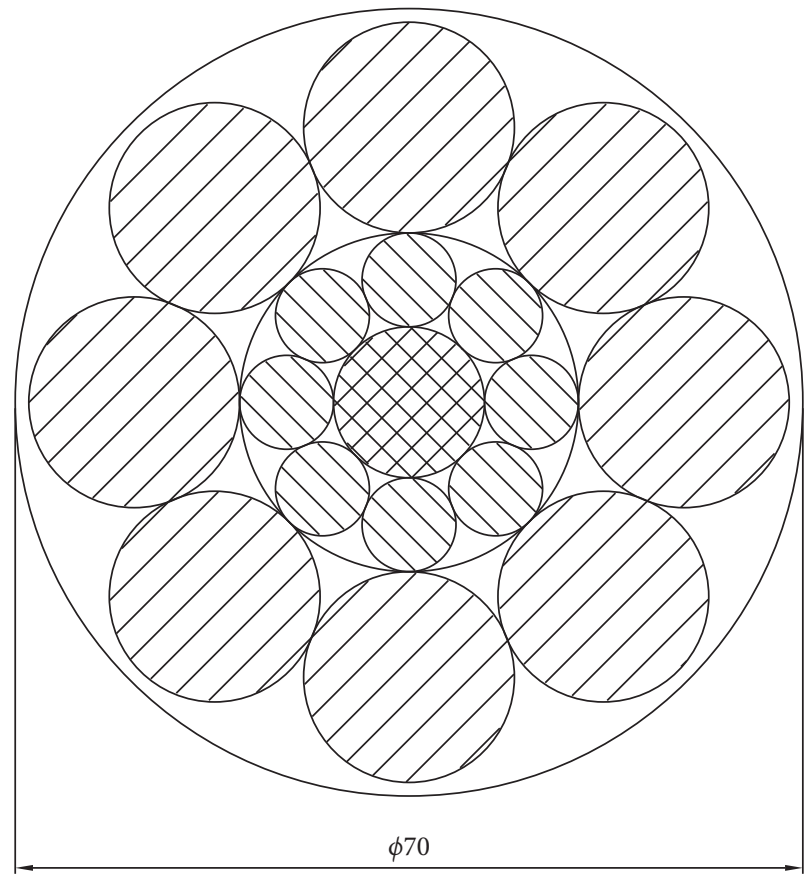

FIGURE 3: Cross-section arrangement diagram of the suspender cable.

first be divided into multiple rectangular parallelepiped grids in FDS, and each grid has the same properties; that is, the temperature and flow velocity in each grid must be the same and the law of change over time must be the same. The coordinate system is defined by the size and location of the tanker fire source. The length of the fire source is along the $x$ axis, the width is along the $y$-axis, the height is along the $z$ axis, and the coordinate origin is defined as the center of the fire, as shown in Figure 4. The size of the tanker flame source is 12 meters along the $x$-axis and 2.5 meters along the $y$-axis. The cross-sectional dimension of the bridge is 32.5 meters, and the size of mid-span model of the bridge is 32.5 meters in the $y$ direction (transverse bridge). The vertical distance of the main cable at the mid-span is 6 meters from the top of the upper steel girder, and the total height of the upper and lower stiffening girders is 11.6 meters; therefore, the size of the mid-span bridge model is 17.6 meters in the $z$ direction (vertical). The calculation shows that, as the tanker is burning at the mid-span suspender cable, the mid-span suspender cable is greatly affected and the two suspender cables adjacent to the mid-span cables are affected minimally. Therefore, in the process of tanker combustion, it is sufficient to take the distance between the three suspender cables as the influence region along the bridge length, and 

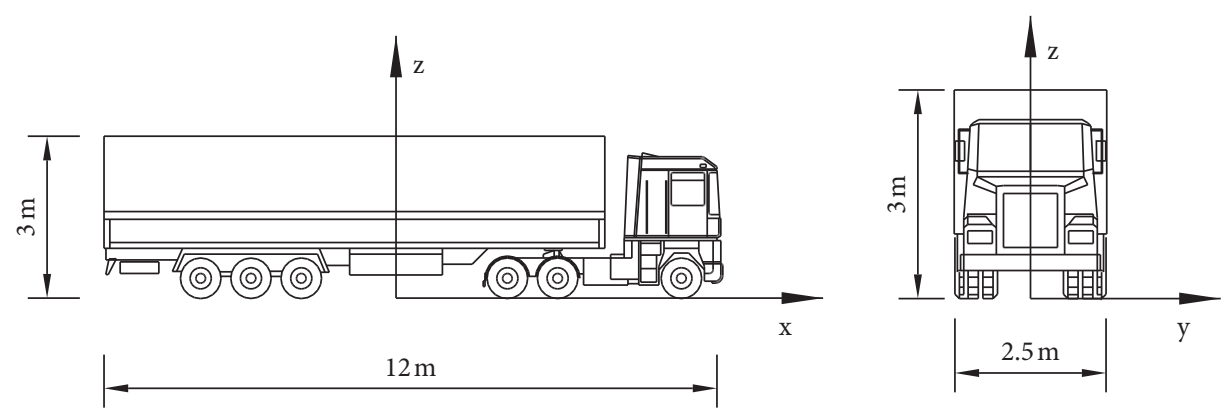

FIGURE 4: Flame source size and the coordinate system of tanker combustion.

the distance between the three slings in the $x$ direction is 36 meters, which is adopted in this model.

In the calculation of the thermal analysis model, the initial temperature is $20^{\circ} \mathrm{C}$ of room temperature, the medium around the bridge is air, and it is assumed that the thermophysical properties (thermal conductivity and specific heat) of air vary significantly with temperature. They are calculated using the values given in Table 1 . The temperature field of corresponding parts varies with time and is measured at the thermocouple points of the suspender cable, main cable, truss vertical, diagonal, upper, and lower chords, top and bottom steel girders, web, and stiffener.

The finite element software ANSYS was used to establish the finite element model of Yangsigang Yangtze River Bridge. The top plate, bottom plate, beam web, stiffener, and truss rod of the steel beam at the mid-span refined section adopt shell63 elements, the deck pavement adopts solid 45 solid elements, and the main cables and slings adopt solid45 solid elements. Beam188 elements are used for the top plate, bottom plate, crossbeam webs, and stiffeners of other parts of the steel beam, link10 elements are used for truss rods, main cables, and slings, and beam 188 elements are used for bridge towers. The rigid domain rigid connection method can make the translation and rotation of the nodes consistent in the threedimensional space with 6 degrees of freedom. The full bridge has a total of 361248 nodes and 322514 elements.

The main cables and slings have circular cross sections. In order to obtain the unique solution of the temperature field of the bridge structure at a specific time, it is necessary to determine the initial conditions and boundary conditions. The initial condition is the initial value of the temperature in the calculation area at the time of the fire, and the boundary condition is the heat transfer form and law between the structure and the surrounding gas. The boundary size of the model grid is 52 meters along the length of the bridge, 40 meters along the width, and 24 meters along the height. The grid is accordingly divided into 52 segments, 40 segments, and 24 segments. Instead of the slings, main cables, truss vertical, diagonal, upper, and lower chords, top and bottom steel girders, webs, and stiffeners, refined grids were utilized according to the details of components. The model had a total of 364820 grids.

3.2. Dangerous Fire Scenario Settings of the Yangtze River Bridge. The most unfavorable fire scenario under the high temperature for the mechanical properties of the bridge is used to calculate the fire resistance and determine the design of suspension bridge. The upper structure of the suspension bridge consists of a stiffening girder, main cable, suspender cable, and bridge tower, which are the main strengthening components of a suspension bridge. From studies of the high-temperature mechanical properties of a four-span suspension bridge with a single layer and three towers, the most dangerous fire scenario is as follows: the longitudinal direction of the tanker combustion is located along the main span of the bridge and the lateral direction is located along the outside lane beside the suspender cable. In this position, the vertical height of the suspender cable is at its lowest and the distance is at its shortest from the fire source; therefore, the impact of the fire is at its greatest.

Owing to the particularities of the double-deck bridge space structure, the fire-resistance calculation of the doubledeck bridge differs considerably from that of the single-layer bridge. When the fire in the tanker breaks out at the upper lane of the bridge, the main cable and sling sustain considerable damage. The stiffening beam is located below the flame, and because of the insulation effect of the bridge deck pavement, the fire does little damage to the stiffening beam. Meanwhile, as the suspension bridge tower is far from the traffic lane and the bridge tower is made out of concrete, the fire has a limited effect on it. When the fire in the tanker breaks out at the lower lane of the bridge, the lower stiffening beam is minimally affected, but owing to the convection and radiation of the flame, the fire has a great impact on the truss bar and the upper stiffening beam. Under the action of dead load and live load on the bridge deck, the web of the upper stiffening end cross beam is subject to a combination of bending and shear stresses. At the same time, the bottom slab of the end cross beam is affected by compressive stress and its elastic modulus decreases with temperature; thus, the bridge is most likely to experience local buckling instability before it collapses. Therefore, the components of the doublelayer suspension bridge that are significantly affected by the fire are the main cable, sling, upper stiffening end cross beam, and truss rod.

Based on the above principles, two dangerous fire scenarios in the upper and lower layers are set in this study: (1) the longitudinal direction of tanker combustion is located at the main mid-span of the bridge, and the transverse direction is towards the main cable and suspender cable of the outermost lane. In this scenario, the high-temperature 
TABLE 1: Thermophysical properties of air $(p=1.01325 \times 105 \mathrm{~Pa})$.

\begin{tabular}{lccccccccccccc}
\hline$T$ & 0 & 100 & 200 & 300 & 400 & 500 & 600 & 700 & 800 & 900 & 1000 & 1100 & 1200 \\
$\rho$ & 1.29 & 0.95 & 0.75 & 0.62 & 0.52 & 0.46 & 0.40 & 0.36 & 0.33 & 0.30 & 0.28 & 0.28 & 0.24 \\
$c$ & 1.01 & 1.01 & 1.03 & 1.05 & 1.07 & 1.09 & 1.11 & 1.14 & 1.16 & 1.17 & 1.19 & 1.20 & 1.21 \\
$\lambda$ & 2.44 & 3.21 & 3.93 & 4.60 & 5.21 & 5.74 & 6.22 & 6.71 & 7.18 & 7.63 & 8.07 & 8.50 & 9.15 \\
\hline
\end{tabular}

Note: $T$ : temperature $\left({ }^{\circ} \mathrm{C}\right) ; \rho$ : density $\left(\mathrm{kg} / \mathrm{m}^{3}\right) ; c$ : specific heat $(\mathrm{kJ} /(\mathrm{kg} \cdot \mathrm{K})) ; \lambda$ : thermal conductivity $\left(10^{-2} \mathrm{~W} /(\mathrm{m} \cdot \mathrm{K})\right)$.

mechanical properties of the main cable and suspender cable are primarily studied. (2) The longitudinal direction of tank combustion is located at the main mid-span of the lower bridge, and the transverse direction is located at the nonmotorized vehicle lanes outside the crash barrier. Thus, the scenario focuses on the high-temperature mechanical properties of the truss rod and the upper stiffening steel beam and plate.

As the entire bridge structure is divided into the upper and lower layers, there are many kinds of components.

\section{Transient Temperature Field Study of the Yangtze River Bridge during the Tanker Fire}

4.1. Analysis of the Transient Temperature Field of the Outermost Upper Lane of the Tanker. The duration of the tanker fire is about $90 \mathrm{~min}$. The maximum duration selected for this study was $90 \mathrm{~min}$. During the fire, the transient temperature field of the fire source and the key parts of the bridge is calculated. The temperature of the fire source changes over time as shown in Figure 5. The ignition temperature rises rapidly in the first $22 \mathrm{~min}$. After reaching $1200^{\circ} \mathrm{C}$ at the $22 \mathrm{nd}$ min, it stayed almost stable, fluctuating between $1200^{\circ} \mathrm{C}$ and $1250^{\circ} \mathrm{C}$.

Owing to the convection and radiation of the flame, the temperature of the surrounding component rises rapidly. The highest point of the suspender cable of the mid-span of the bridge from the main girder is 6 meters, and the transverse direction of the suspender cable is about 3 meters away from the fire. After the fire, the suspender cable will be surrounded by the flame produced by the tanker and as the sectional dimension of the suspender cable is small (the diameter is Ф70), the center and the outermost temperatures of the suspender cable are basically the same during the fire. The temperature of the suspender cable exceeds $900^{\circ} \mathrm{C}, 32 \mathrm{~min}$ after the fire, and then tends to stabilize, as is shown in Figure 6.

The high temperature will make the elastic modulus and tensile strength of suspender cable decrease significantly, as shown in Figure 7. Before the fire, with the suspender cable temperature rising slowly, the elastic modulus and tensile strength decrease slightly. After $16 \mathrm{~min}$, the temperature of the steel wire of the suspender cable increased rapidly and the elastic modulus and tensile strength decreased significantly. The elastic modulus had decreased to 0.01 at room temperature for $36 \mathrm{~min}$, and the elastic modulus was basically lost. After $36 \mathrm{~min}$, the tensile strength had decreased from 1 to 0.19 at room temperature.

The diameter of the main cable is $1 \mathrm{~m}$. Owing to the large cross-sectional area of the cable, the temperature distributions of the outermost and innermost layer of the main cable are not uniform. In this study, the main cable temperature is

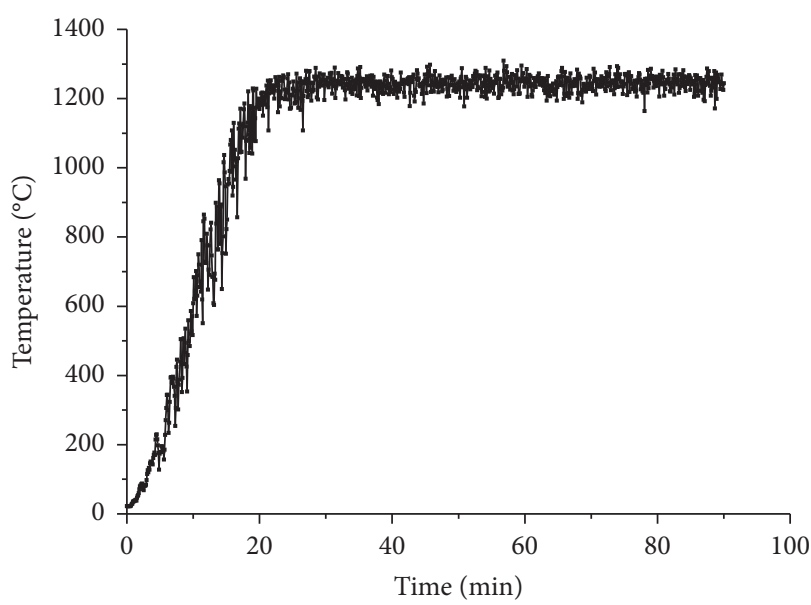

Figure 5: Temperature changes of the fire source over time.

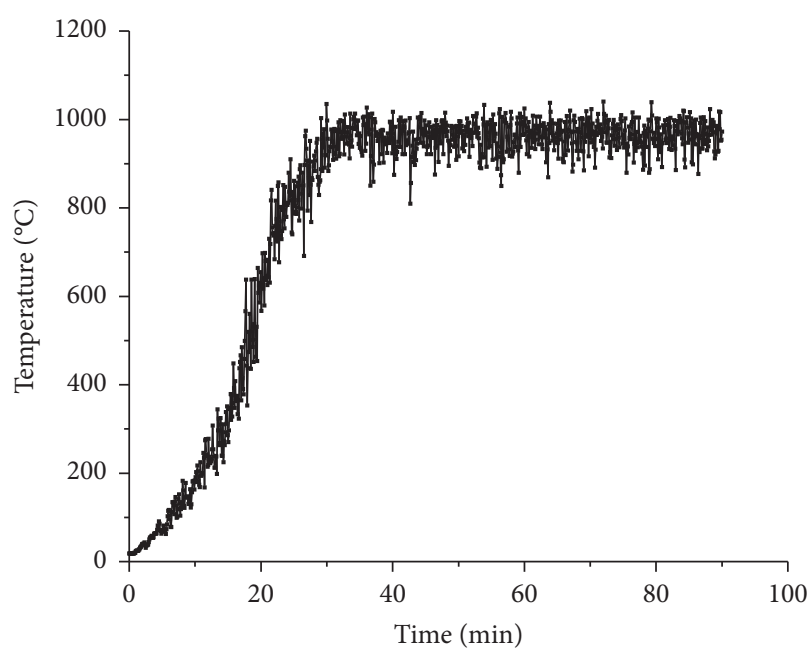

Figure 6: Temperature curve of the suspender cable.

defined as the average temperature of the outermost layer and the innermost layer. The main cable temperature rose slowly during the first 14 th $\mathrm{min}$, and then, the rise rate increased. At the 36th min, the temperature of the main cable was more than $600^{\circ} \mathrm{C}$. It then fluctuated at $670^{\circ} \mathrm{C}$ before stabilizing, as shown in Figure 8.

Similar to the suspender cable, high temperature can reduce the elastic modulus and tensile strength of the main cable. The elastic modulus of the main cable decreased slowly after the first $18 \mathrm{~min}$, and the descending rate increased between 18 and $38 \mathrm{~min}$. The elastic modulus had decreased to less than 0.3 times its value at room temperature at the 42nd min, and then, it tended to be stable. The tensile strength of the main cable decreased slowly after the first 


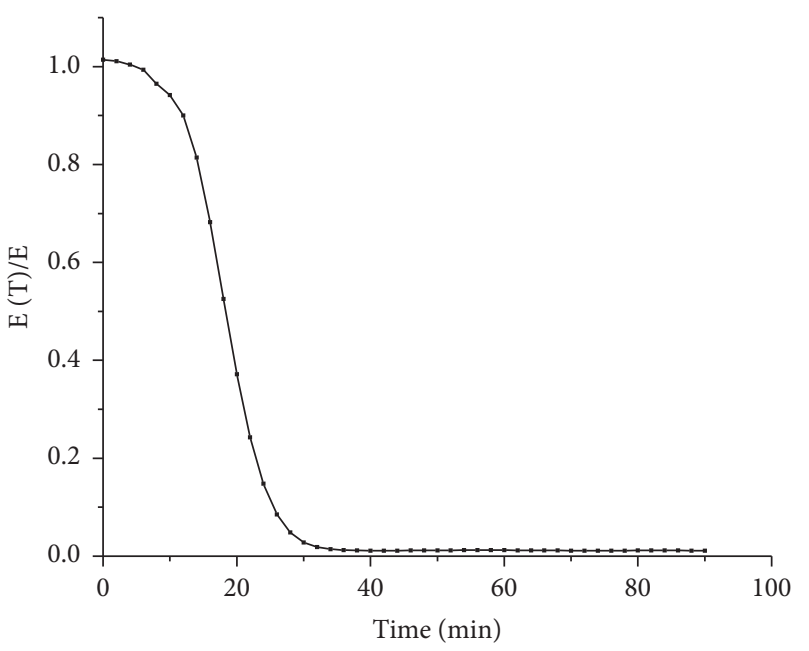

(a)

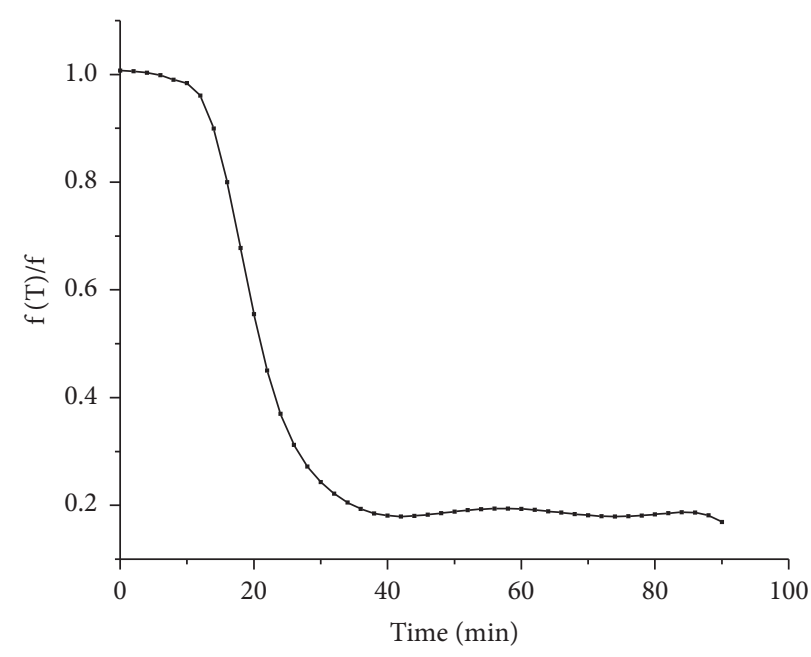

(b)

Figure 7: (a) Elastic modulus and (b) tensile strength curves of the suspender cable.

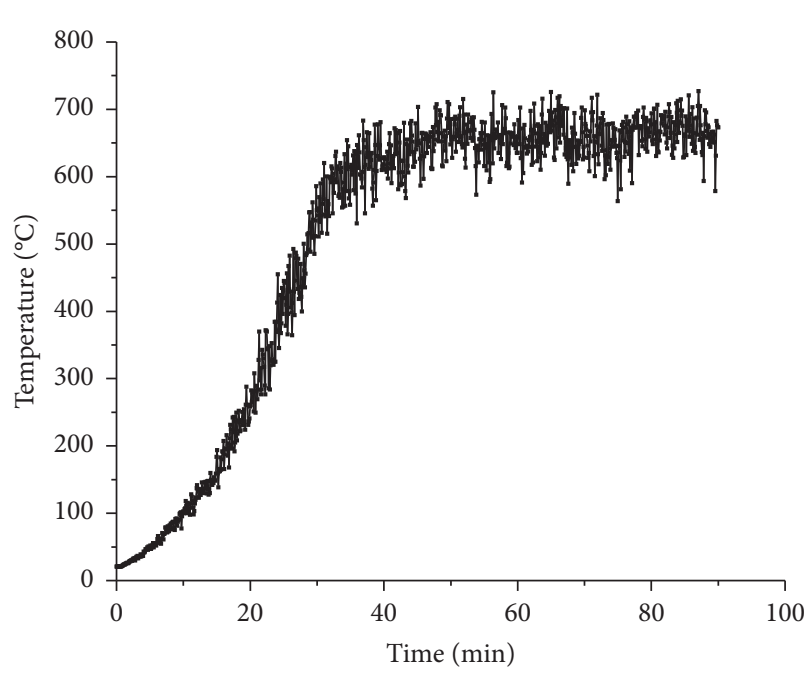

FIgURE 8: Temperature change curve of the main cable.

$20 \mathrm{~min}$, and the descending rate increased between 20 and $40 \mathrm{~min}$. The tensile strength decreased to 0.5 times of its value at room temperature and then became stable, as shown in Figure 9.

Owing to the high temperature generated by combustion of the tanker, the deck pavement temperature will rise rapidly and then transmit heat to the stiffening girder roof and upper chord. The upper layer temperature of the bridge deck pavement rose to a maximum rate between 12 and $26 \mathrm{~min}$, and the temperature was higher than $900^{\circ} \mathrm{C}$ at $32 \mathrm{~min}$; then, it tended to be stable. The temperature of the stiffening girder roof increased owing to heat conduction from the deck pavement. The observed trend of the heating rate was similar to that of deck pavement, and the temperature rise lagged behind that of the deck pavement. At $40 \mathrm{~min}$, the temperature was $450^{\circ} \mathrm{C}$, and then, it remained stable, as shown in Figure 10.

The elastic modulus and strength of the upper stiffening girder varied with the change of temperature, but when the maximum temperature was lower than $500^{\circ} \mathrm{C}$, the reduction range was relatively small and the temperature dropped to 0.6 times of room temperature, as shown in Figure 11.

Due to the conduction of heat by the upper stiffening girder roof, the temperatures of the cantilevered diaphragm and the longitudinal stiffener of the upper stiffening girder roof increased, but owing to the lack of thermal radiation and convection, the maximum temperature was much lower than of the pavement on the deck and the heating rate was relatively low. The temperature of the longitudinal stiffener of the upper stiffening girder roof was greater than $400^{\circ} \mathrm{C}$ after $48 \mathrm{~min}$, and then, it tended to become stable. The temperature of the cantilever diaphragm increased almost linearly in the first $50 \mathrm{~min}$, reaching $300^{\circ} \mathrm{C}$ after $52 \mathrm{~min}$, and then, it became stable, as shown in Figure 12.

At the 58th min, the elastic modulus of the longitudinal stiffener of the upper steel girder was only 0.71 times its value at room temperature and the strength had decreased to 0.82 times its value at room temperature. The elastic modulus of the cantilever diaphragm was 0.87 times its value at room temperature after $58 \mathrm{~min}$, and its strength decreased to 0.94 times of its value at room temperature.

When the tanker burned, the maximum temperature of the vertical stiffener of the upper cantilever diaphragm was low (about $220^{\circ} \mathrm{C}$ ) and the mechanical properties basically remained the same. The maximum temperature reached by the tanker during combustion was about $330^{\circ} \mathrm{C}$. The heating rate was small, and the maximum temperature was relatively low, as shown in Figure 13.

From the above results, it is shown that when the tanker burns in the outermost lane of the upper bridge structure, the fire has a significant impact on the main cable and suspender cable of the bridge. The elastic modulus and the tensile strength of the main cable and suspender cable will be greatly reduced as the temperature rises abruptly. The temperature of the steel plate of the upper stiffening girder will rise relatively slowly due to the deck pavement, and the elastic modulus and strength will decrease slightly, which improves the safety of the bridge. 


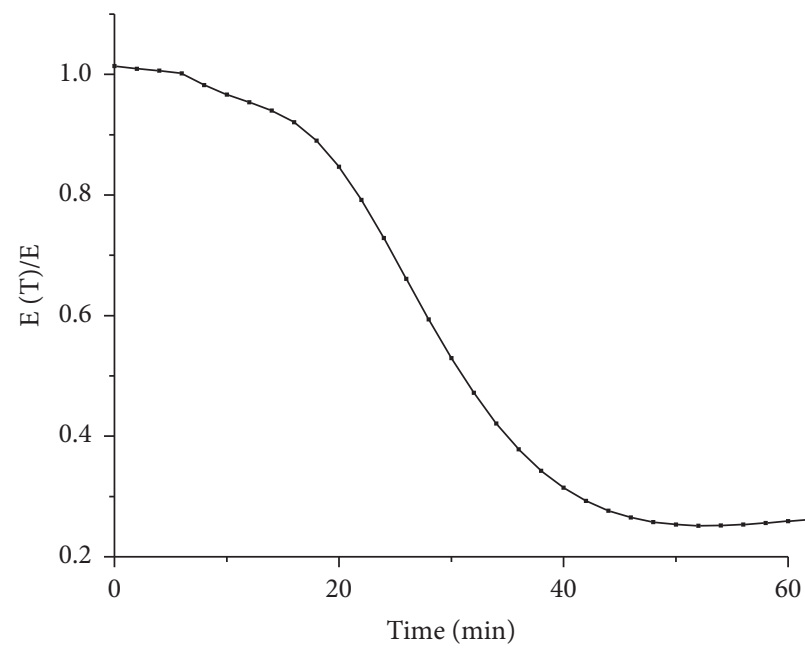

(a)

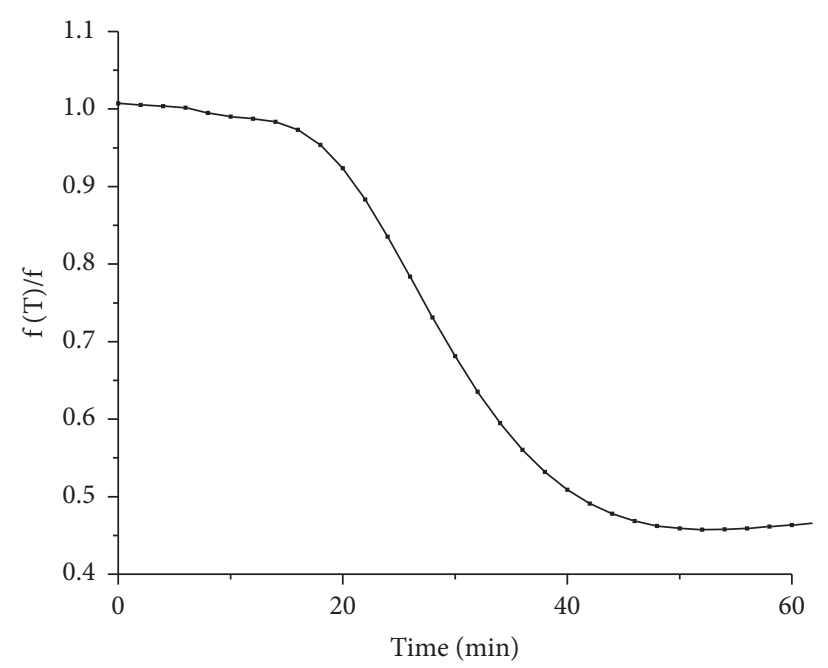

(b)

FIGURE 9: Changes in the (a) elastic modulus and (b) tensile strength of the main cable.

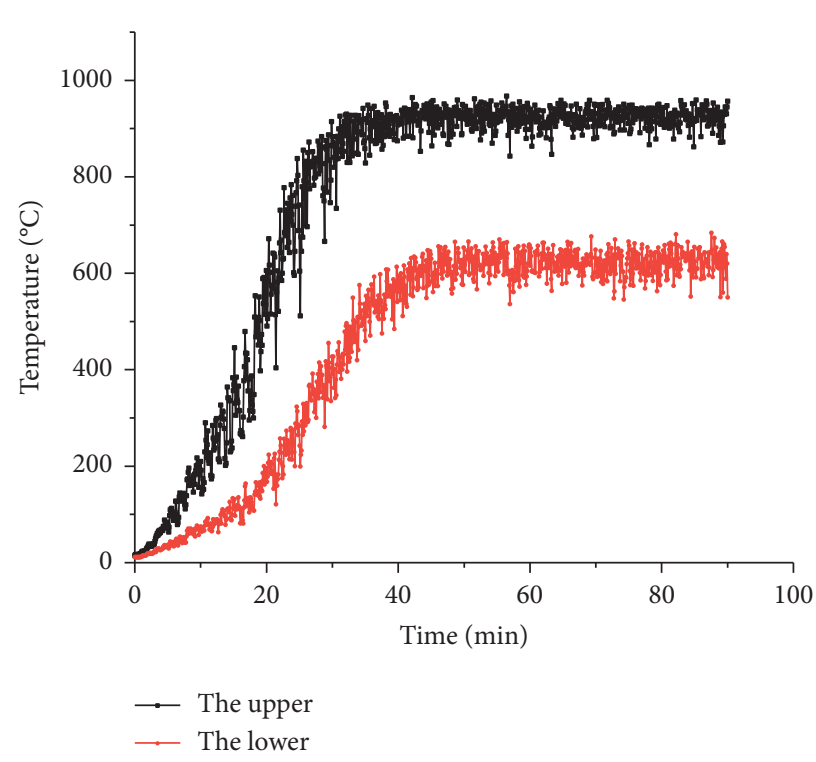

(a)

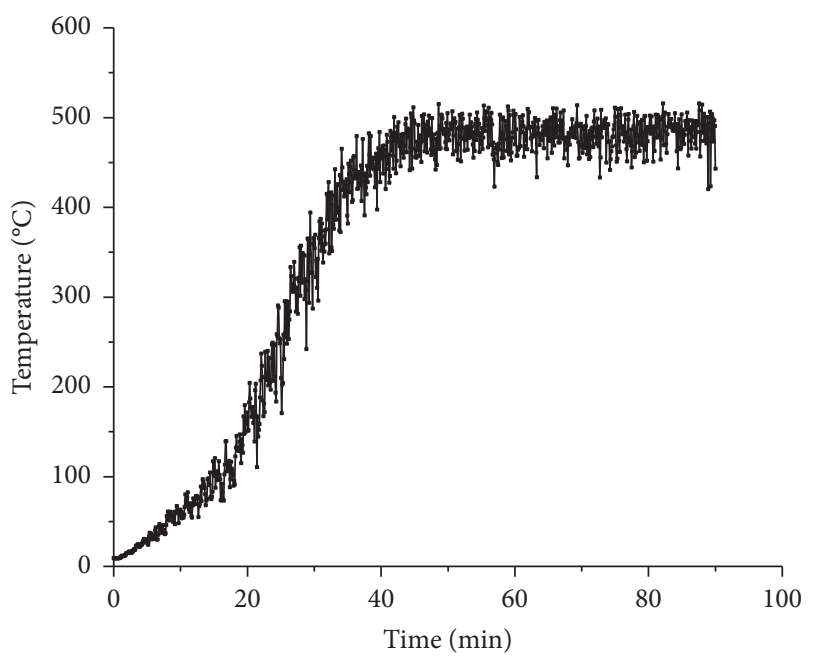

(b)

FIGURE 10: Temperature curve of the (a) bridge deck pavement and (b) upper stiffening girder roof.

\subsection{Analysis of Transient Temperature Field Combustion at} the Upper Middle Lane of the Tanker. When the tanker burns at the upper middle lane, the distance from the flame to the suspender cable is far from the distance of the outermost lane combustion, so the warming trend is different from a fire that occurs at the lane. Furthermore, the maximum temperature reached in both scenarios is different. The temperature of the suspender cable rose at a lower rate in the first $16 \mathrm{~min}$, and the ascending rate was higher between $16 \mathrm{~min}$ and $34 \mathrm{~min}$. After 42 minutes, the temperature stabilized. The overall heating rate was lower than that of the tanker in the outermost lane. The final temperature was about $700^{\circ} \mathrm{C}$, which was lower than the temperature when the tanker burns in the outermost lane $\left(966^{\circ} \mathrm{C}\right)$, as shown in Figure 14.

Sixteen minutes before the fire, the elastic modulus and tensile strength of the sling decreased slightly due to the slow heating rate. After $16 \mathrm{~min}$, the temperature of the suspender cable steel wire is increased rapidly and the decline rate of elastic modulus and tensile strength is increased. The elastic modulus decreased to less than 0.3 times of its value at room temperature at $44 \mathrm{~min}$ and finally decreased to 0.22 times of its value at room temperature when the burning came to an end. The tensile strength decreased to 0.5 times of its value at room temperature at $44 \mathrm{~min}$ and finally decreased to 0.43 times of its value at 


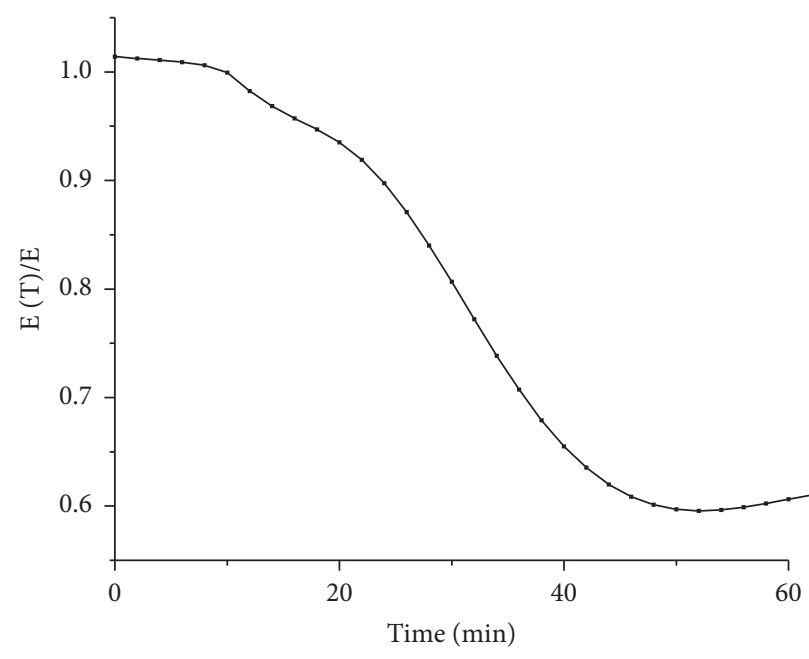

(a)

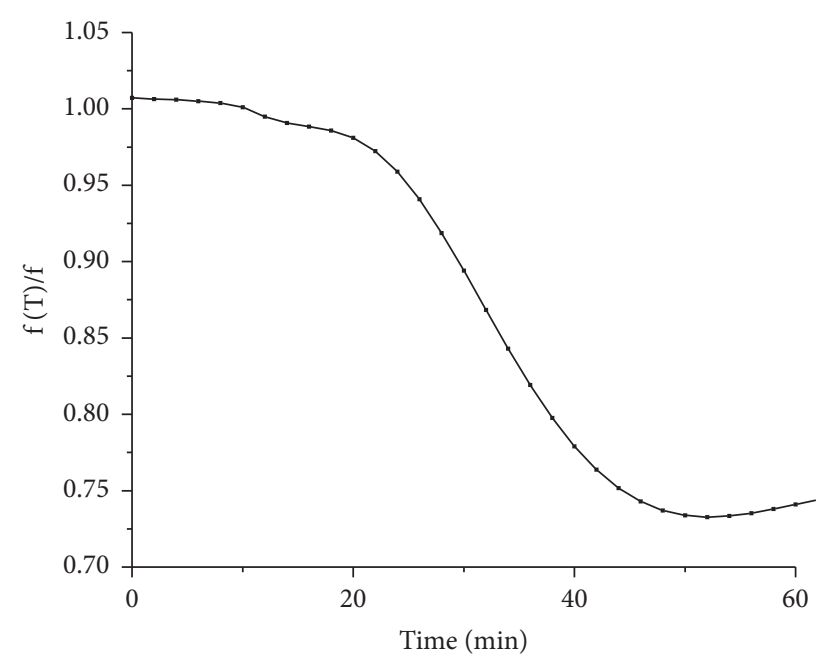

(b)

FIGURE 11: (a) Elastic modulus and (b) tensile strength curve of the stiffening girder roof.

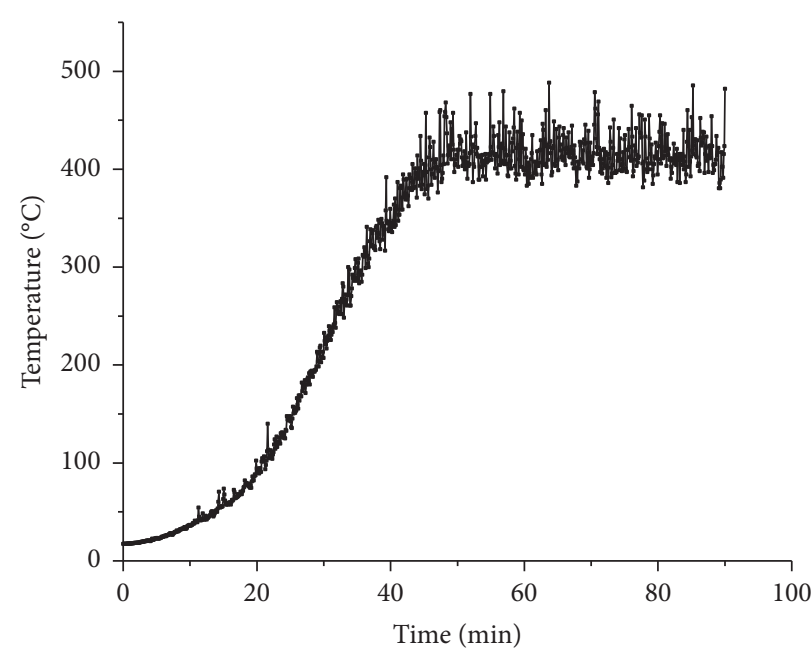

(a)

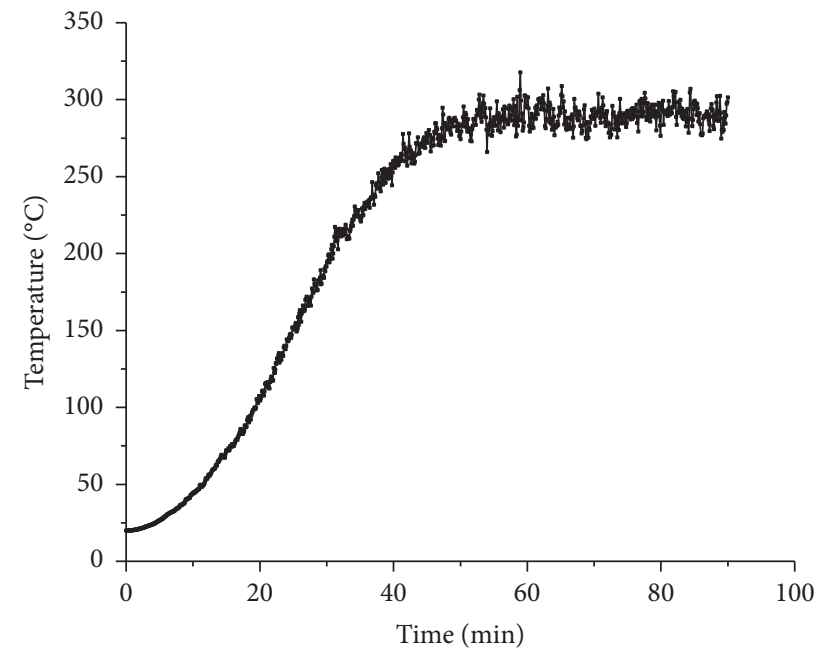

(b)

Figure 12: Temperature field and curves of the (a) steel beam roof stiffener and (b) cantilever diaphragm.

room temperature when the burning came to an end, as shown in Figure 15.

The main cable temperature rose slowly during the first $16 \mathrm{~min}$, and the rising rate increased between the 16th $\mathrm{min}$ and 36th min. At the 36th min, the main cable temperature is higher than $400^{\circ} \mathrm{C}$, and then, it tended to be stable and fluctuated at $490^{\circ} \mathrm{C}$. The heating rate and the maximum temperature reached by the main cable are significantly smaller than those of the tanker burning at the outermost lane, as shown in Figure 16.

The elastic modulus of the main cable decreased slowly in the first $14 \mathrm{~min}$, and the decline rate increased between the 14th and 40th min. The elastic modulus decreased to less than 0.6 times of its value at room temperature at the 74th min, and then, it tended to be stable. The tensile strength of the main cable decreased slowly in the first $20 \mathrm{~min}$, and the decline rate increased from 20 th $\mathrm{min}$ to 42 th $\mathrm{min}$. The tensile strength decreased to 0.72 times of its value at room temperature at the 80th min and then tended to be stable. It can be seen that when the tanker burns at the upper middle lane, the fire has a smaller impact on the main cable and suspender cable than when the tanker burns at the outermost lane, as shown in Figure 17.

From the above results, it shows that when the tanker burns at the upper middle lane of the bridge, the effects on the main cable and suspender cable of bridge are small and the rates at which the elastic modulus and tensile strength of the main cable and suspender cable decrease are much smaller than those when the tanker burns at the upper middle lane of the bridge. Burning at Lower Nonmotorized Vehicle Lanes. The lower 


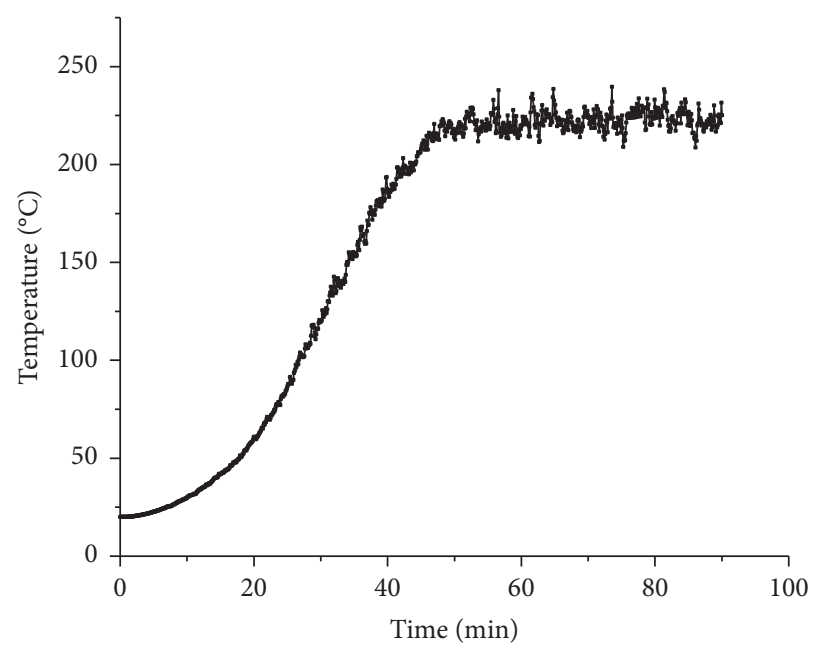

(a)

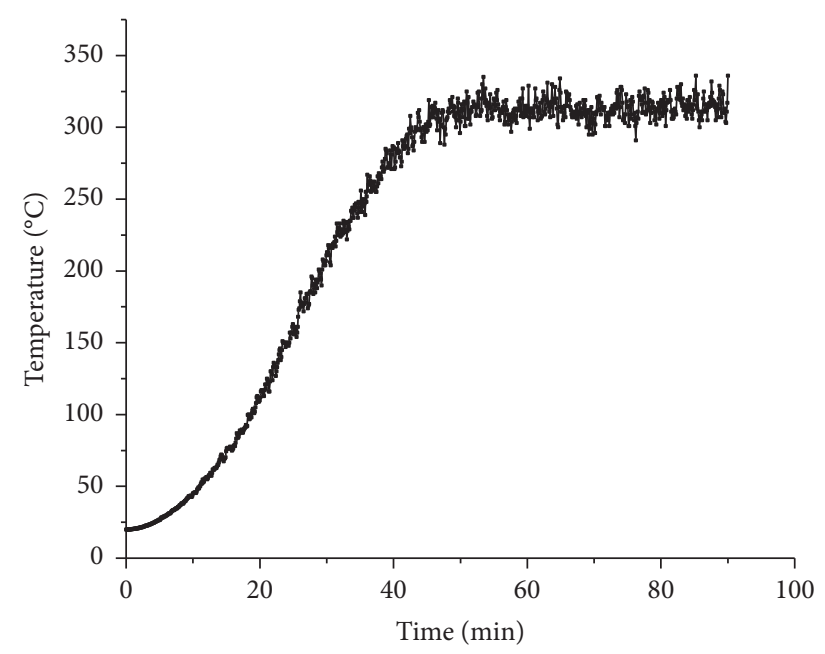

(b)

FIgURE 13: Temperature field and curves of the (a) vertical web stiffener and (b) upper chord.

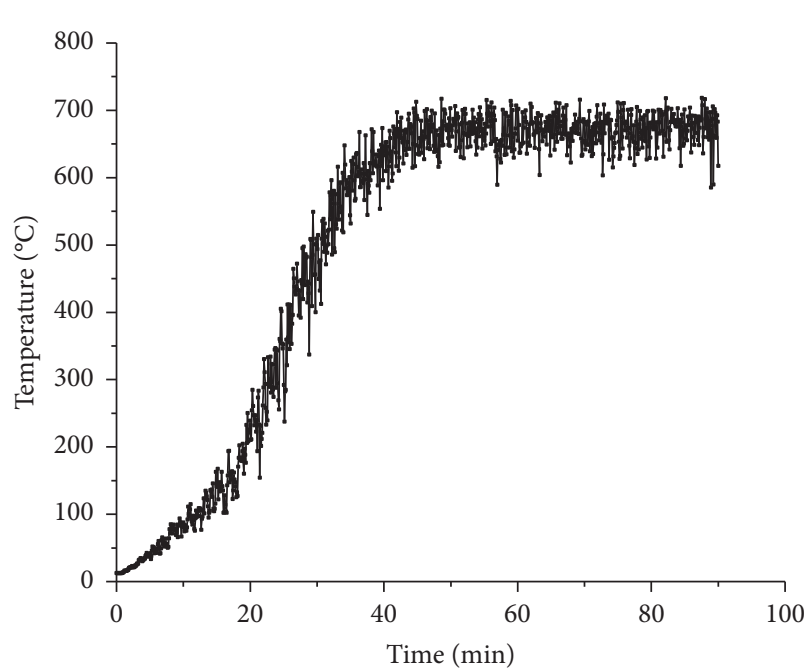

FIgURE 14: Temperature curve of the mid-span suspender cable.

bridge consists of two-way four lanes, and the outer lane is nonmotorized vehicle lane. In this study, the calculation took into account the most adverse extreme case, that is, when the tanker breaks through the fence of the nonmotorized lane, it crashes into the lane and begins to burn. When the tank burns at the lower nonmotorized vehicle lane, the temperature field of the upper stiffening beam and the lower stiffening beam is obtained.

The bottom slab of the upper steel girder was directly exposed to the tanker fire, and this caused the temperature to rise rapidly. The heating rate was lower in the first $18 \mathrm{~min}$ but increased after $18 \mathrm{~min}$, and the temperature was higher than $900^{\circ} \mathrm{C}$ in the 48th min. It then fluctuates steadily around $940^{\circ} \mathrm{C}$. The temperature fields are shown in Figure 18.

At the 18th min before the fire, the elastic modulus decreased slightly due to the slow temperature rise in the upper steel beam plate. After $18 \mathrm{~min}$, the temperature of the upper steel girder plate increased rapidly and the modulus of elasticity decreased significantly. The strength decreased slightly in the first $24 \mathrm{~min}$, and then, the rate of decreasing is increased, as shown in Figure 19.

The temperature of the upper steel girder roof will increase under the action of convection and radiation, but as the heat absorbed by the roof is partly used by the deck pavement, the rate of temperature increase is slightly slower than that of the web. The temperature rises slowly in the first $24 \mathrm{~min}$ and rapidly between the 24th min and the 42nd min. The temperature was greater than $700^{\circ} \mathrm{C}$ at the $52 \mathrm{nd}$ min and then became stable, as shown in Figure 20.

Twenty-four minutes before the fire started, the elastic modulus of the upper steel girder roof decreased slightly. After $24 \mathrm{~min}$, the elastic modulus decreased significantly, as the heating rate increased. At the 52nd min, the elastic modulus decreased to 0.20 times of its value at room temperature and then became stable. The descending rate of the strength lagged behind that of the elastic modulus. At the 58 th $\mathrm{min}$, the rate decreased to 0.4 times of its value at room temperature, as shown in Figure 21.

When the tanker burns at the lower nonmotorized lane, the upper steel girder is directly exposed to the flame and has a higher temperature. The external surfaces of the vertical bar and diagonal bar are also greatly affected. The temperature of vertical bar 1 increased rapidly, as it is nearer the combusting tanker. The rising rate was low in the first $16 \mathrm{~min}$, but it increased after $16 \mathrm{~min}$. The temperature was greater than $800^{\circ} \mathrm{C}$ at the 34 th $\mathrm{min}$, and then, it became stable. Vertical bar 2 is close to vertical bar 1 . Although it is far from the fire source and its temperature is lower than that of vertical bar 1, it is still affected by the fire source. The temperature rising rate was lower in the first $18 \mathrm{~min}$, but it increased after $18 \mathrm{~min}$, reaching a temperature greater than $600^{\circ} \mathrm{C}$ at the 52nd min; then, it became stable and fluctuated at $600^{\circ} \mathrm{C}$, as shown in Figure 22.

Sixteen minutes before the fire started, since the rate at which the temperature of vertical bar 1 increased was low, the elastic modulus decreased slightly. After $16 \mathrm{~min}$, the temperature of vertical bar 1 increased rapidly and the elastic 


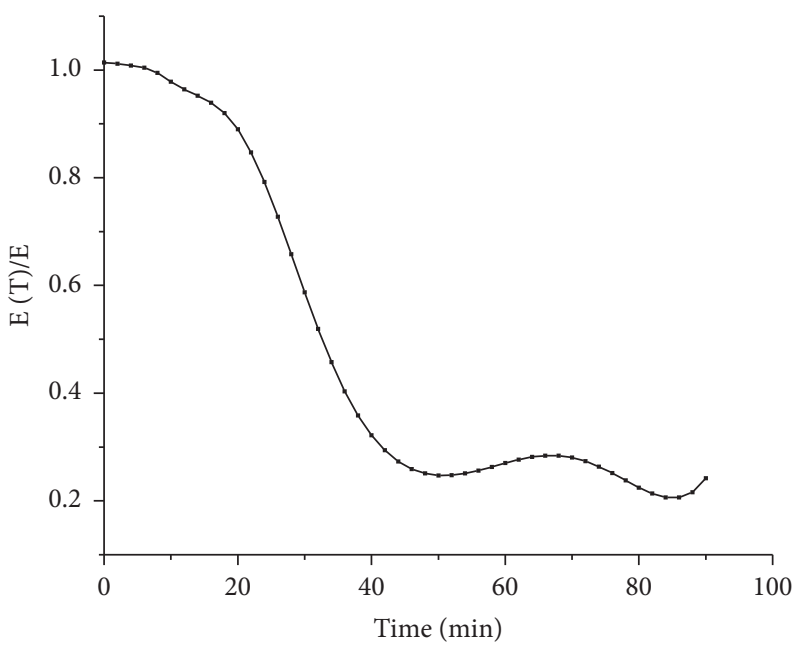

(a)

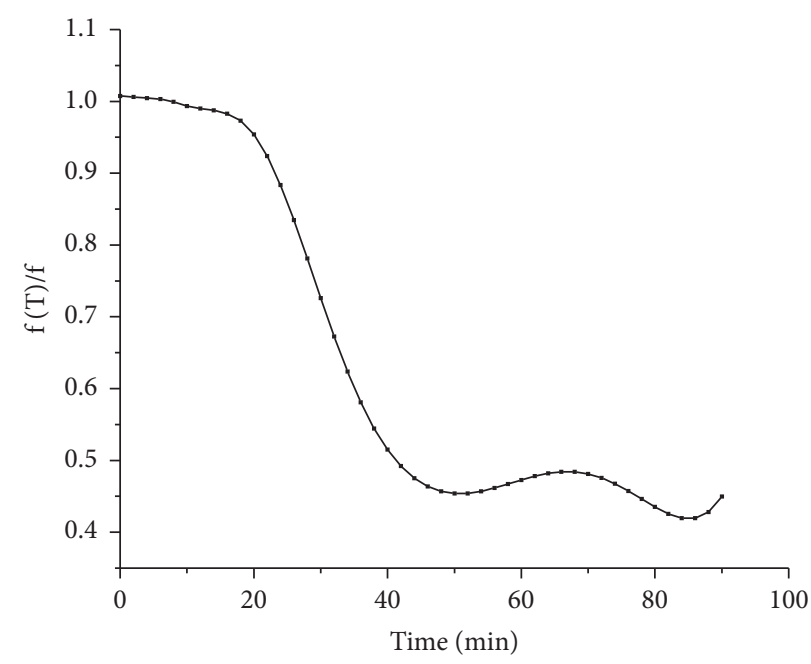

(b)

Figure 15: (a) Elastic modulus and (b) tensile strength curve of the mid-span suspender cable.

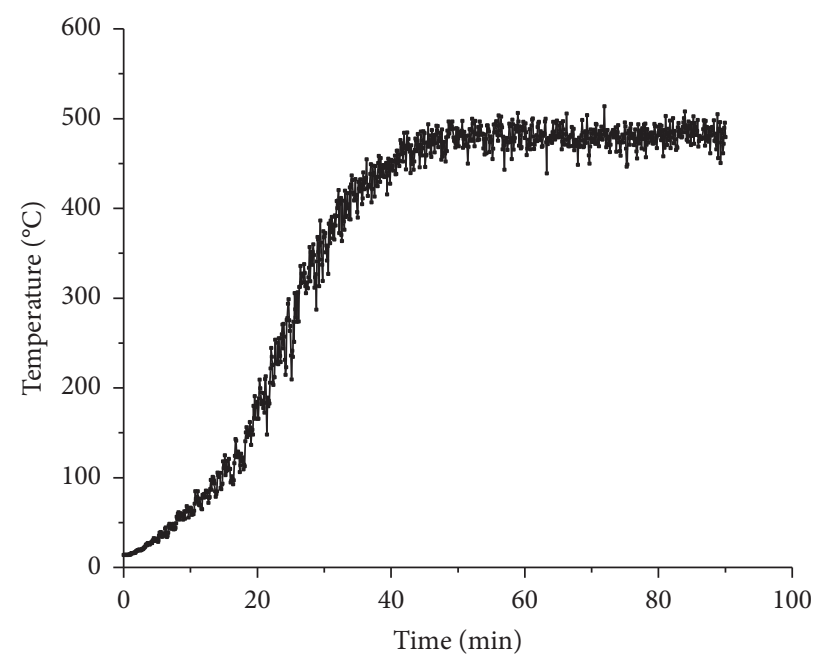

FIGURE 16: Temperature curve of the mid-span main cable.

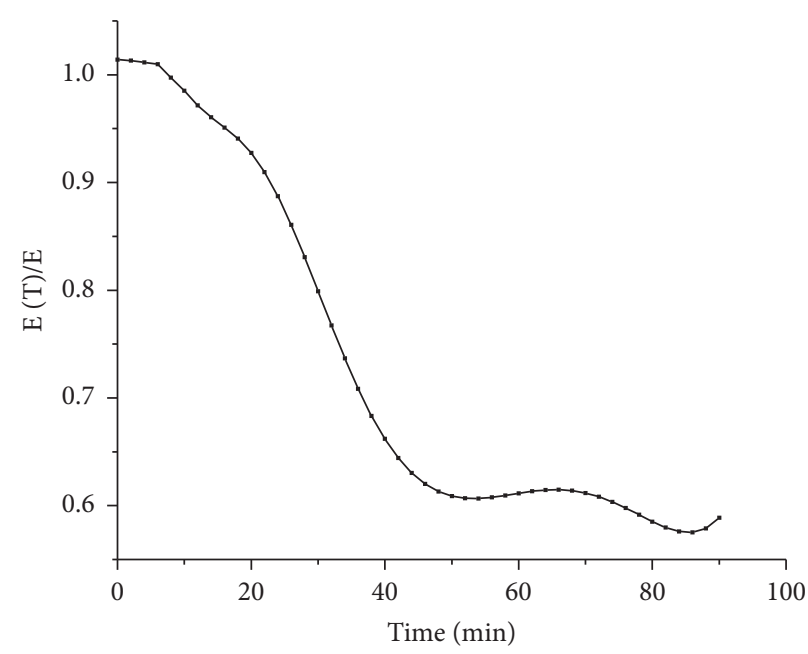

(a)

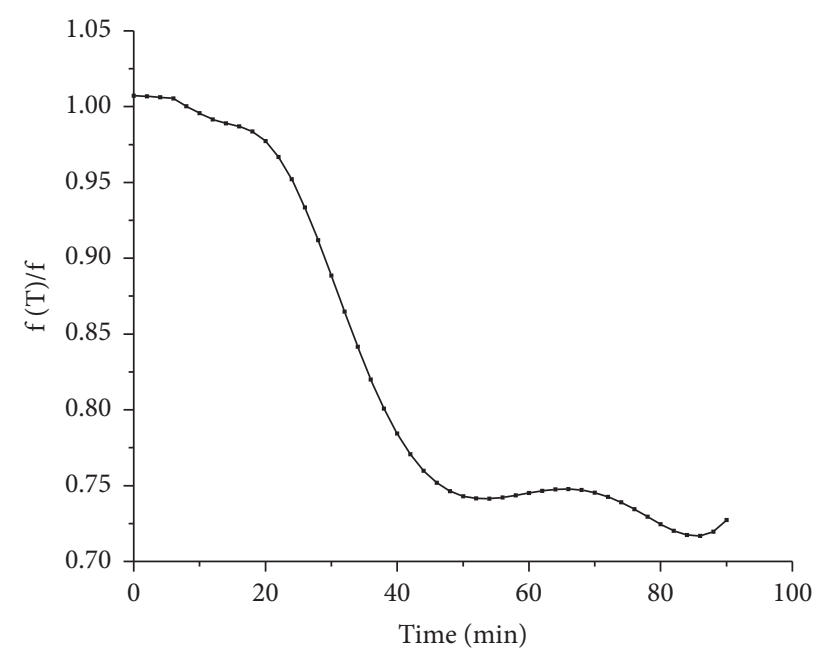

(b)

FIgURE 17: (a) Elastic modulus and (b) tensile strength curve of the main cable. 


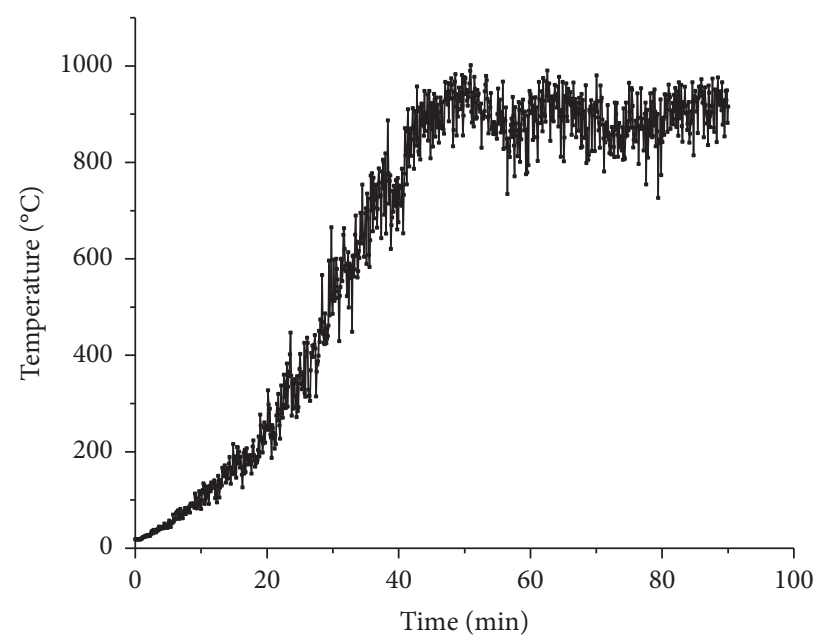

FIgURE 18: Temperature curve of the upper steel girder plate.

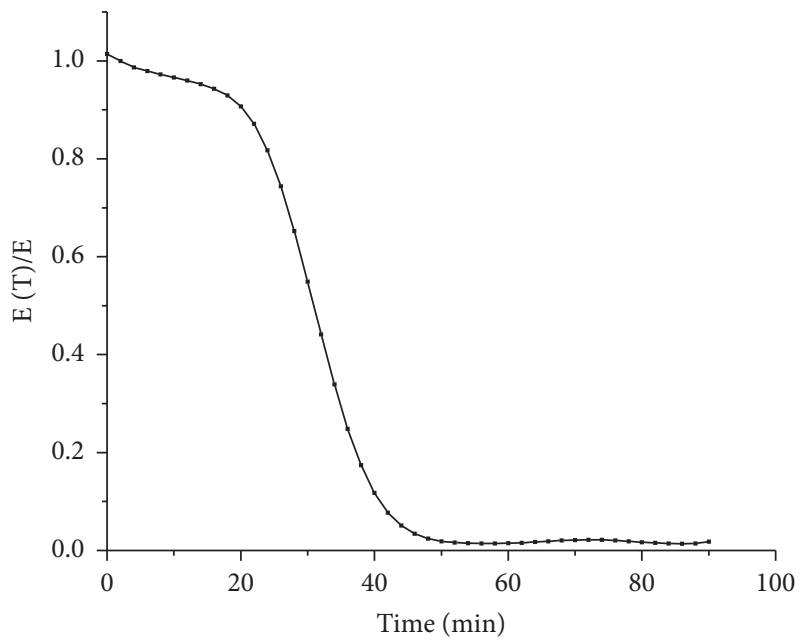

(a)

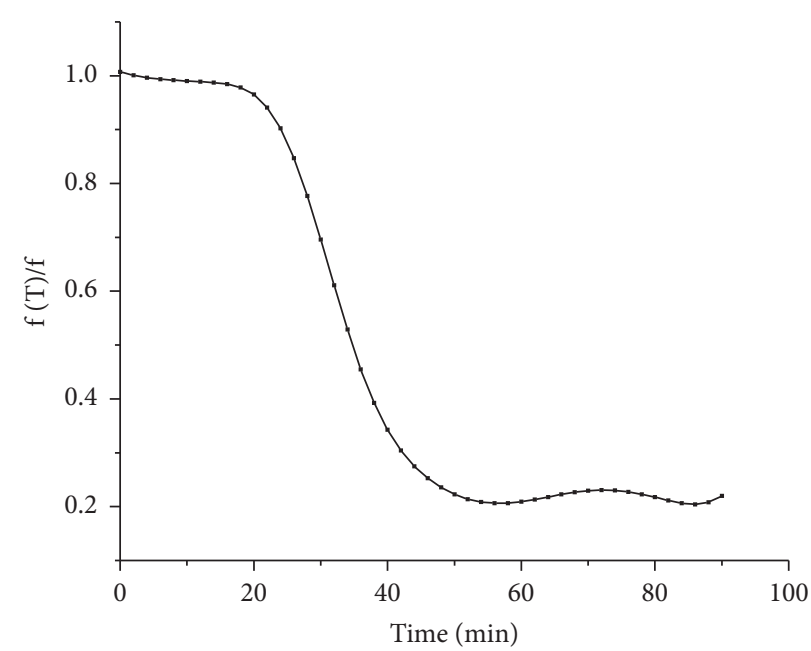

(b)

FIgURE 19: (a) Elastic modulus and (b) tensile strength curve of the upper steel girder plate.

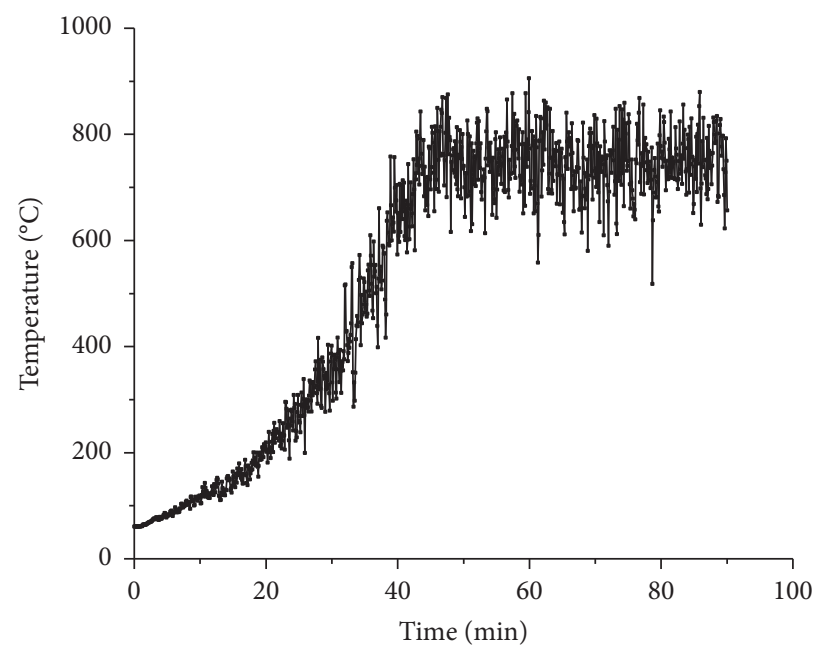

Figure 20: Temperature curve of the upper steel girder roof. 


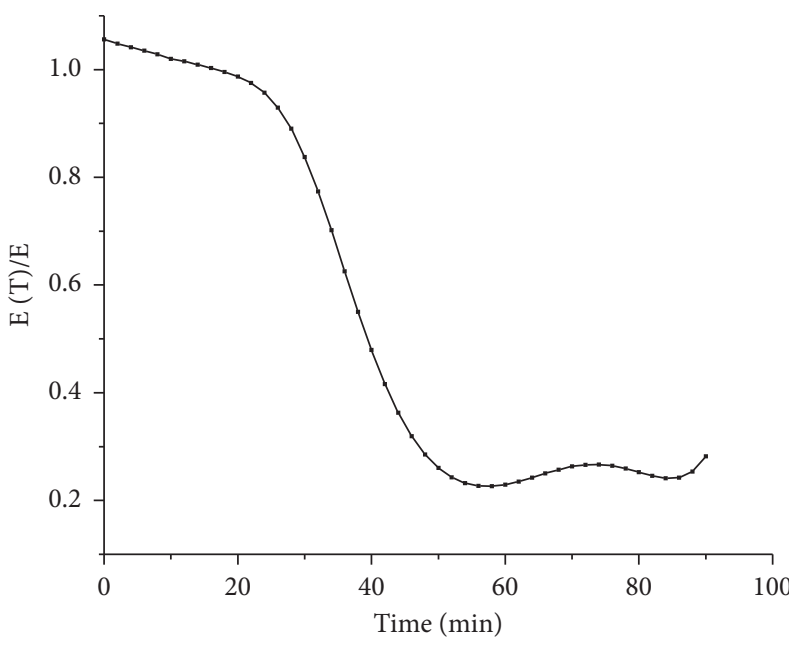

(a)

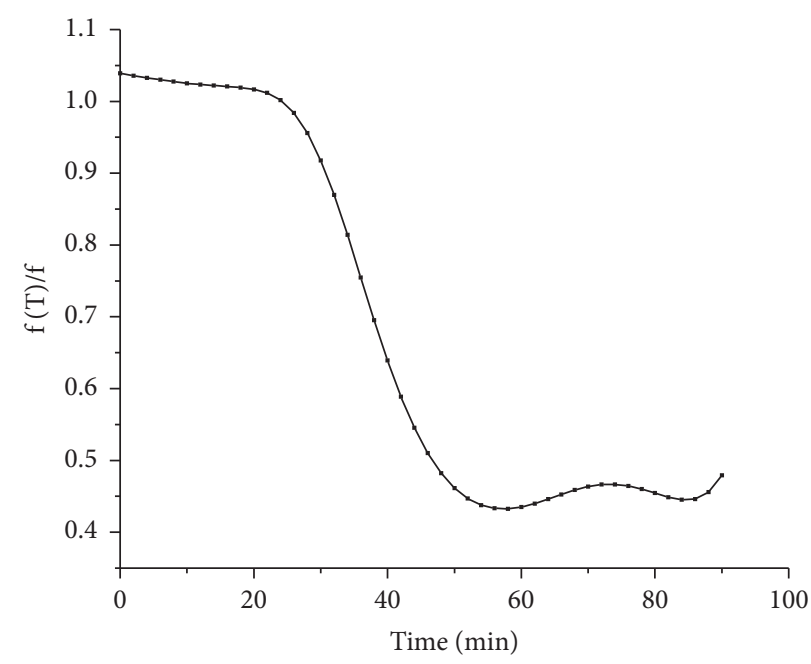

(b)

FIgURE 21: (a) Elastic modulus and (b) tensile strength curve of the steel girder roof.

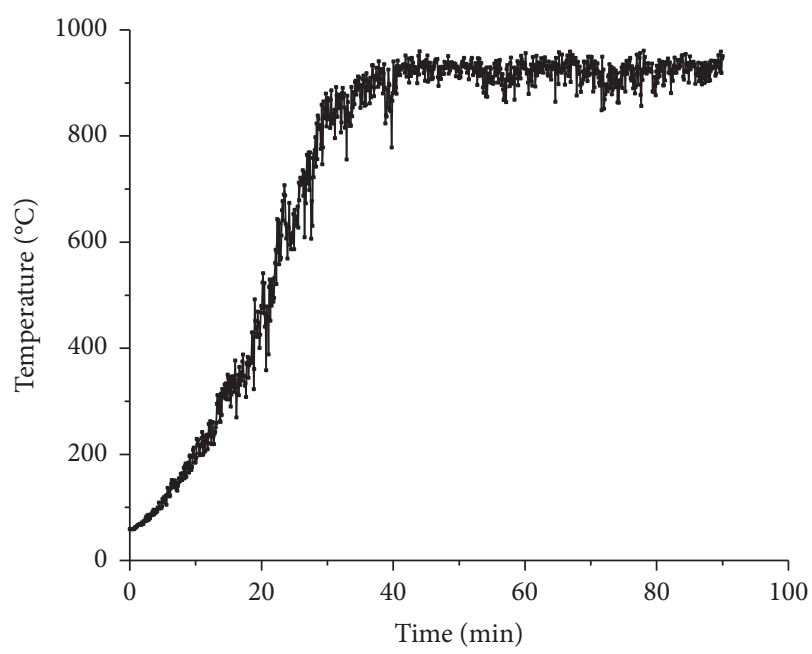

(a)

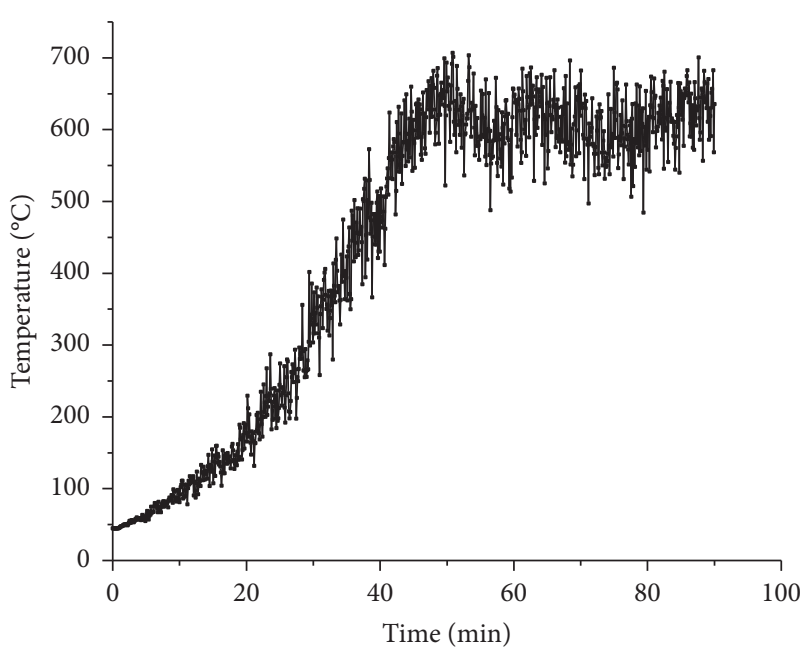

(b)

FIgURE 22: Temperature field cloud and curve of (a) vertical bar 1 and (b) vertical bar 2.

modulus decreased significantly. The change in the strength is slightly lagged behind that of the elastic modulus. Twentysix minutes before the fire started, since the rate at which the temperature of vertical bar 2 increased was low, the elastic modulus decreased slightly; however, after $26 \mathrm{~min}$, the temperature rising rate of the vertical bar 2 increased and the elastic modulus decreased significantly. The variation in the strength is slightly lagged behind that of the elastic modulus.

The temperature of the diagonal also increased rapidly under the action of tanker combustion. The maximum temperature was slightly lower than that of vertical bar 1 . The rising rate of the diagonal was lower in the first $16 \mathrm{~min}$, but it increased after $16 \mathrm{~min}$. The temperature was greater than $800^{\circ} \mathrm{C}$ at $44 \mathrm{~min}$; then, it tended to be stable and fluctuated at around $850^{\circ} \mathrm{C}$.

The upper chord also reached a higher temperature during combustion of the tanker. The temperature rising rate was low in the first $18 \mathrm{~min}$, but after $18 \mathrm{~min}$, the rising rate increased. The temperature was greater than $600^{\circ} \mathrm{C}$ at $46 \mathrm{~min}$ and then it became stable and fluctuated at around $620^{\circ} \mathrm{C}$. Due to the heat insulation effect of the deck pavement, the maximum temperature reached by the lower chord during combustion of the tanker was about $330^{\circ} \mathrm{C}$. The temperature rising rate was low and the influence by the fire was small.

The results above indicate that, when the tanker burned at the lower nonmotorized vehicle lane, the upper stiffening of the steel plate and truss were greatly affected. The temperature of the upper stiffening roof, bottom plate, cantilever diaphragm, stiffener, and truss vertical and diagonal chords increase greatly owing to convection and radiation of the flame, and the corresponding elastic moduli and strengths decrease greatly.

The stress of the sling increased slowly 20 minutes before the fire. As the temperature of the sling during this time 


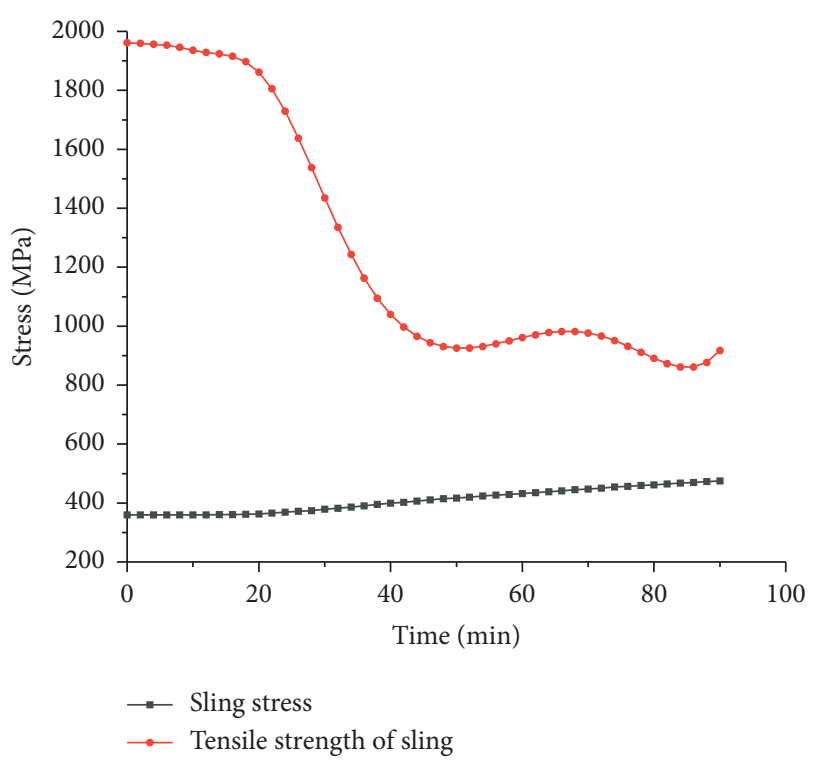

FIGURE 23: Curve diagram of sling stress and tensile strength over time.

period was relatively low, the stress of the sling remained basically unchanged. After 20 minutes, due to the increase in temperature, since the elastic modulus and strength of the sling at this temperature are greatly affected by the temperature, the sling stress increases, basically showing a linear increase. When the fuel tank-truck burns, the sling stress increases to $397.8 \mathrm{MPa}$ and the tensile strength of the sling drops to $840.7 \mathrm{MPa}$. At this time, the sling stress is less than the tensile strength and the sling will not be damaged during the combustion phase of the tanker truck, as shown in Figure 23.

The main cable stress maintained a low rate of rise during the entire fire phase. At the end of the fuel tanker's combustion, the main cable stress increased from 797.9 $\mathrm{MPa}$ at room temperature to $923.6 \mathrm{MPa}$, with a small stress increase. The tensile strength of the main cable is reduced to $1425.6 \mathrm{MPa}$ at the end of the fuel tanker's combustion, which is much greater than the stress of the main cable. Therefore, the main cable will not be damaged during the combustion phase of the upper middle lane of the bridge. The main cable has a higher strength safety reserve, as shown in Figure 24.

When a fire occurs in the upper middle lane of a tanker, since the maximum temperature and heating rate reached by the main cable and sling are lower than of the fire in the outermost lane of the upper layer of the tanker, the increase rate of the deflection of the main beam in the middle of this scene is relatively low. The outermost lane of the upper tank car is different under the fire. The deflection rise rate of the main girder in the middle of the span changes significantly at three time periods. At $0-18 \mathrm{~min}$, due to the lower temperature of the main cable sling, the deflection rise rate of the main girder at this stage is relatively low and the deflection is at $18 \mathrm{~min}-44 \mathrm{~min}$. The rise rate increases. The increase in the rate at this stage is mainly affected by the changing mechanical properties of the main cable sling at

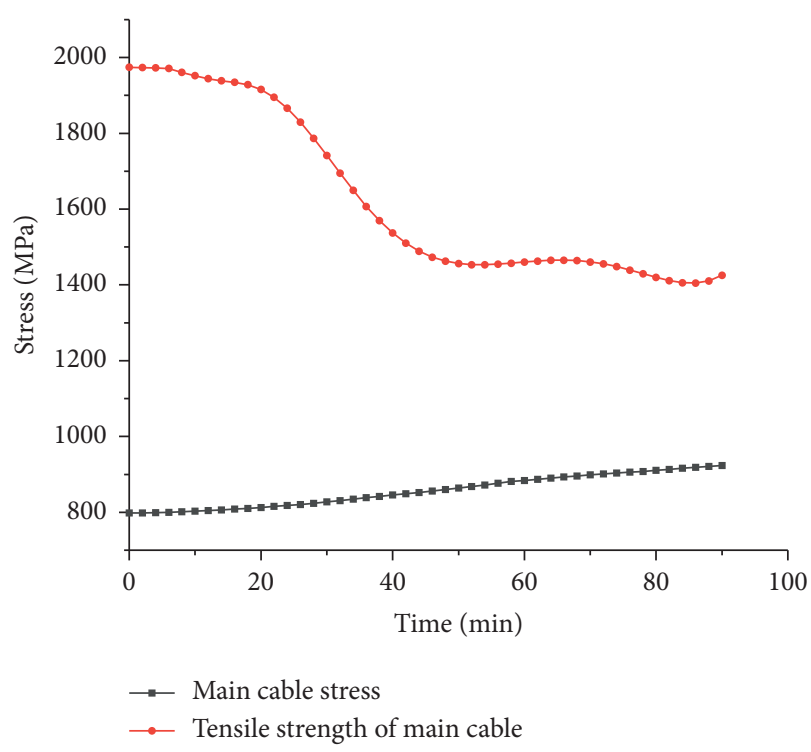

FIGURE 24: Curve diagram of main cable stress and tensile strength change with time.

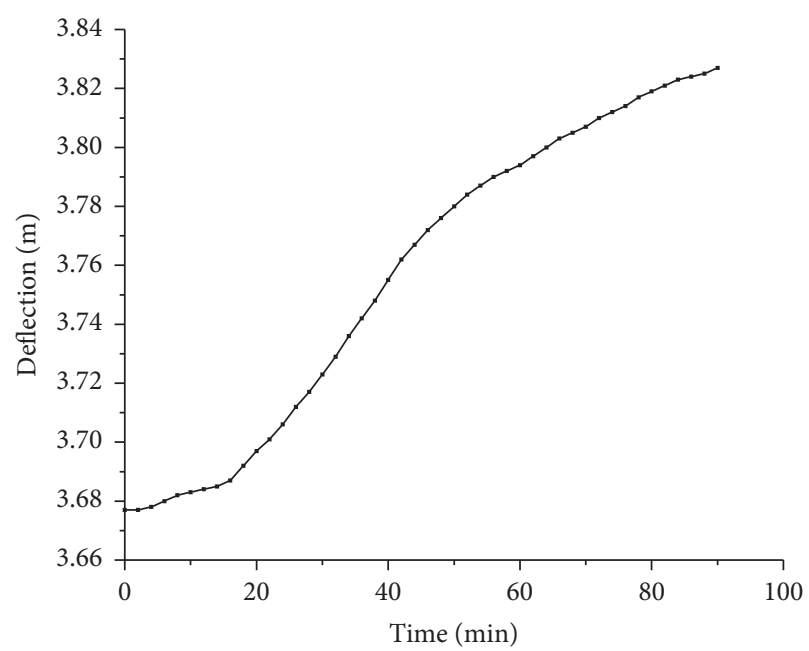

FIGURE 25: Deflection curve diagram of the mid-span of the bridge.

high temperatures. The deflection rise rate decreases again at $44 \mathrm{~min}-90 \mathrm{~min}$, because the temperature of the main cable sling has stabilized within a certain range. At the end of the fuel tanker's combustion, the deflection of the main beam increases to $3.827 \mathrm{~m}$, as shown in Figure 25 .

The calculation results show that when a fire occurs in the middle lane of the upper bridge, the tanker will have less impact on the main cables and slings of the bridge and the main cables and slings will not be damaged. Therefore, when the oil tank truck passes through the bridge from the upper layer of the bridge, it can be guided by the bridge management department to pass through the middle lane of the bridge.

\section{Conclusion}

In this paper, the three-dimensional thermal model of Wuhan Yangtze River Bridge is established by using Fire 
Dynamics software (FDS). The 3D temperature field distribution characteristic of the bridge in different parts was obtained, and the thermal analysis results are applied to the suspension three-dimensional finite element model of ANSYS. The mechanical properties of the main cable, sling and stiffening beam at high temperature are calculated by means of thermal-structure coupling analysis.

Results show that the tensile strength and elastic modulus of the main cable and sling decrease rapidly with the increase in temperature. The failure regularity of the cable system of the double-deck suspension bridge at high temperature and the buckling deformation characteristics of the steel plate of the stiffening girder under high temperature are determined. Under the action of dead load and live load, when the tanker burns in the outermost lane of the middle main span of the bridge, the shortest failure time of the suspension cable is $36 \mathrm{~min}$ and the shortest failure time of the main cable is $58 \mathrm{~min}$. When the tanker burns in the lower nonmotorized lane of the middle main span of the bridge, the shortest failure time of buckling of the steel plate is $43 \mathrm{~min}$, and failure of the local buckling, rather than the strength of the bridge structure, firstly occurs at this time.

\section{Data Availability}

The testing and analysis data used to support the findings of this study are included within the article.

\section{Conflicts of Interest}

The authors declare that there are no conflicts of interest regarding the publication of this paper.

\section{Authors' Contributions}

Conceptualization was performed by Y. M. and Y. X.; methodology was provided by G. X.; data curation was carried out by W. H.; the original draft was prepared by H. T and C. Q.; reviewing and editing were performed by C. Q. All authors have read and agreed to the published version of the manuscript.

\section{Acknowledgments}

This study was partly sponsored by the Nanning City "Yongjiang Project" Funded Project (2018-01-04); Guangxi Natural Science Foundation (2020GXNSFAA159150); National Natural Science Foundation of China (nos. 51738004, 51868006, and 51878186); Cultivation Project Jointly Founded by Guangxi Natural Science Foundation (2018GXNSFAA138067); Guangxi Science and Technology Plan Project (AB17292018); Guangxi Science and Technology Major Project (AA18118055); Guangxi University High Level Innovation Team and Outstanding Scholar Program (GJR [2018] No. 35); project supported by Nanning "Yongjiang Plan" (20180104); Nanning Excellent Young Scientist Program (RC20190206); and Science \& Technology Base \& Talent Special Project of Guangxi Province (AD19245152).

\section{References}

[1] I. E. Harik, A. M. Shaaban, and H. Gesund, "United States bridge failures," Journal of Performance of Constructed Facilities, vol. 4, no. 4, 1990.

[2] Battelle, "Comparative risks of hazardous materials and non: hazardous materials truck shipment accidents," U.S. Department of Transportation: FMCSA, vol. 34, 2001.

[3] E. Aziz and V. Kodur, "An approach for evaluating the residual strength of fire exposed bridge girders," Journal of Constructional Steel Research, vol. 88, pp. 34-42, 2013.

[4] K. Venkatesh, A. Esam, and D. Mahmud, "Evaluating fire resistance of steel girders in bridges," Journal of Bridge Engineering, vol. 18, pp. 633-643, 2013.

[5] G. P. Sayol, I. P. Zaforteza, J. M. Alos, and A. Hospitaler, "Analysis of the influence of geometric, modeling and environmental parameters on the fire response of steel bridges subjected to realistic fire scenarios," Journal of Computers \& Structures, vol. 158, pp. 333-345, 2015.

[6] E. M. Aziz, V. K. Kodur, J. D. Glassman, and M. E. Moreyra Garlock, "Behavior of steel bridge girders under fire conditions," Journal of Constructional Steel Research, vol. 106, pp. 11-22, 2015.

[7] S. Z. Liu, C. Ma, W. H. LiLiyuan, and X. Liu, "Assessment and strengthening design of PC box girder subjected to fire damage," Journal of Bridge Construction, vol. 44, pp. 94-100, 2014.

[8] H. Liu, Z. Gao, Q. Liu, and J. Zhang, "Assessment and strengthening of a fire damaged prestressed concrete continuous girder bridge," Journal of Bridge Construction, vol. 81, p. $87,2015$.

[9] F. Heymes, L. Aprin, and A. M. Birk, "An experimental study of an LPG tank at low filling level heated by a remote wall fire," Journal of Loss Prevention in the Process Industries, vol. 26, pp. 1484-1491, 2013.

[10] Y. Q. Li and D. Z. Ma, "Fire protection design calculation and construction treatment of building structures," China Construction Industry Press, vol. 18, 1991.

[11] T. T. Lie and E. M. A. Denham, "Factors affecting the fire resistance of circular hollow steel columns filled with bar: reinforced concrete," Technical Report, National Research Council Canada:CNRC, Ontario, Canada, 1993.

[12] J. Fan and Z. T. Lv, "Experimental study on materials properties of prestressed steel wire post high temperatures," Industrial building, vol. 32, pp. 30-31, 2002.

[13] H. Y. Zhang and W. Z. Zheng, "Mechanical property of steel strand at high temperature," Journal of Harbin Institute of Technology, vol. 39, pp. 861-865, 2007.

[14] W. C. Xue, S. Zhang, and C. Y. Gong, "Progress on fire resistance of prestressed concrete structures," Industrial buildin, vol. 36, no. 12, pp. 60-64, 2006.

[15] Y. Z. Wang, C. G. Fu, and H. X. Qiu, "Study on mechanical property in properties of cold:rolled deformed bar after undergoing high:temperature," Journal of Iron and Steel Research, vol. 17, pp. 31-34, 2010.

[16] Q. F. Wu, Q. Deng, and B. Ma, "Fire:resistance design for double layer of steel structures minpu bridge," ShangHai Highway, vol. 3, no. 1, pp. 22-25, 2010.

[17] C. Wu, F. Jhan, J. Chen, J. Jeng, K. Chen, and H. Yang, "Fabrication and properties of high: Tc YBCO josephson junction and SQUID with variable thickness bridges by focused ion beam," IEEE Transactions on Applied Superconductivity, vol. 21, no. 3, pp. 375-378, 2011. 